\title{
Does Your Online Course Perpetuate Institutional Discrimination?
}

\author{
VERÓNICA L. REYNA | HOUSTON COMMUNITY COLLEGE
}

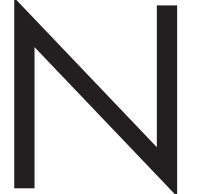

ot me. Not in my course. I protest, sign petitions, and even teach about injustice! Sound familiar? Many of us would never believe that we could unknowingly participate in that horrid phrase "institutional discrimination," but how many of us have thought about how institutional discrimination occurs in the day-to-day details on our campuses? Often, institutional discrimination occurs without discriminatory intent in course design. It's in our mindsets about proper learning, educational standards, rigor, and assumptions about this generation. It's in the unquestioned ways about how we learned that we continue because 'that's just how a college course is done.' We were educated and socialized by, and now educate and socialize in, institutions with checkered pasts (and equally questionable presents). Here's a quick check: write down all the complaints you've ever levied about students. Now reverse engineer them. What are other possible explanations for these behaviors beyond the classic "students these days?"

How can faculty teach with social justice and not just about social justice? How we choose to make our courses can either enable success for all students, or it can systematically privilege success for some students and perpetuate obstacles for others. These obstacles are course-level details and where institution-

\section{How can faculty teach with social justice and not just} about social justice? How we choose to make our courses can either enable success for all students, or it can systemically privilege success for some students and perpetuate obstacles for others.

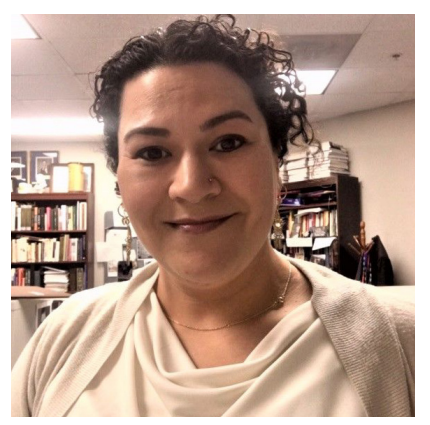

al bias occurs, too. And we all have obstacles in our courses. There's always work for us to do, even if many educators are not perpetuating obstacles they experienced in college. Teaching with social justice requires a more mindful professor who develops a supportive relationship with students built on trust. As we

Verónica L. Reyna is associate chair of the Department of Government at Houston Community College. She teaches Intro to American Government and Texas Government, as well as Mexican American/Latinx Politics. grumble while creating our online courses for the next semester, let us also see the opportunity in creating these courses without biased assumptions that play a role in perpetuating institutional discrimination. A tool we can use to put justice into action is the Social Justice Checklist for Online Course Design, developed this summer for the APSA Virtual Teaching Workshop: Innovative Approaches to Online Teaching.

\section{THE PURPOSE OF THE CHECKLIST}

The Social Justice Checklist provides an operationalized list of course features we know create equity, justice and support all students. The checklist's purpose is not to educate about the research or theories on how course design and educators perpetuate discrimination (though I encourage you to seek out resources). The checklist is designed for quickly transitioning courses online given COVID-19; it can also be used to tweak already-existing online courses. The checklist just tells you what to do for triage purposes; the 'why' you can learn about when you have more time.

The course features listed start with the minimum expectations for ADA accommodations and other course accessibility standards. The next level of features draws from research found in books like Bandwidth Recovery: Helping Students Reclaim Cognitive Resources Lost to Poverty, Racism, and Social Marginalization (2017) by Cia Verschelden. Many high impact practices (HIPs) or best practices of online pedagogy work in part because they empower all students to learn with fewer obstacles. The other resources created in the APSA Online Teaching Innovation Workshop provide ideas for carrying out these best practices, too.

\section{HOW TO USE THE CHECKLIST}

The Social Justice Checklist has three tabs at the bottom of the sheet: Access to Technology and Materials; Restoring Cognitive Bandwidth; and Online Learning Student Mentoring. These tabs represent areas in online courses where access to justice issues occur, and each tab details when they occur in course design. On each sheet, there is a status column with a drop-down menu to track when a course feature is checked and added to a course, or when adding a feature is postponed. The "more information" column directs you to resources that help carry out that specific course feature.

Start with a review of the minimum standards for accessibility. For students with diversabilities, online courses provide new 
obstacles that were once controlled in on-campus instruction. Already existing economic, social, and health disparities have been heightened by the pandemic, so using a broader definition of course accessibility is necessary. Next, work toward mindfulness about course features which help restore cognitive bandwidth. Do assignments prevent extra economic hardship because they consider data usage or limited access to the internet? Does assignment content or wording, or other elements of the course, prevent triggering stereotype threat or imposter syndrome? The course features listed in the second tier of each tab help to address questions like these.

Occasionally return to the checklist; the resource will be expanded and improved. The checklist is a start, and by no means is exhaustive; there will be student experiences that differ across types of colleges and universities, too, as well as across regions of the United States. Suggestions are welcomed to help make the checklist more inclusive. n April we added a new feature to APSA Preprints, APSA's open research repository, to enable authors to initiate a submission straight from APSA Preprints to the American Political Science Review, Perspectives on Politics, and PS: Political Science \& Politics. If you have a preprint accepted to APSA Preprints, you'll be able to easily transfer information about it over to the journals' submission sites, getting your submission started with minimum hassle.

This new feature was identified as particularly valuable as part of the active user research that goes in to developing the site, so we're excited to be launching it now.

\section{WHY START WITH POSTING A PREPRINT?}

While the new feature will allow more convenient submission directly from APSA Preprints, the involved journals already accept submissions that have been previously posted as preprints. Posting work in its early stages can offer great benefits to subsequent publication. Not only do preprints offer the opportunity for public commenting and feedback from the political science discipline, posting early can build an audience for your work ahead of formal publication.

\section{HOW DO PREPRINTS AFFECT THE DOUBLE BLIND PEER REVIEW PROCESS?}

The journals offering this feature still operate a double-blind peer review process, in which the peer reviewers and authors do not know one another's identities when the review is taking place. For this reason, we will be asking authors who use the APSA Preprints direct submission feature to upload an anonymized PDF once logged into the submission system for each journal, and ensure that their submission meets all of the requirements of the particular journal to which the submission is directed.

While posting a preprint does publicly identify you as the au- thor of a work, some best practice is emerging around preprints in the context of double-blind review. As is usual, peer reviewers are expected not to search for the work online during review, and they are also required to declare if they know the identity of the author(s). The latter can happen, for example, if research has previously been presented at a conference. With these measures in place, the editorial team at each of the journals can take steps to ensure the integrity of the peer review process.

\section{WHAT OTHER FEATURES WILL BE ADDED TO APSA PREPRINTS?}

APSA Preprints will be continuously developed over time, in collaboration with Cambridge University Press, who provide the underlying technology. Features developed since the site was launched include the addition of commenting, event collection pages, and, more recently, several improvements to the accessibility of the site-and we plan to continue to work closely with users to identify new features and improvements. If you have suggestions for features you'd like to see, please get in touch with us at preprints@apsanet.org. For detailed instructions on how to submit your preprint to an APSA journal, head to preprints.apsanet.org $\square$

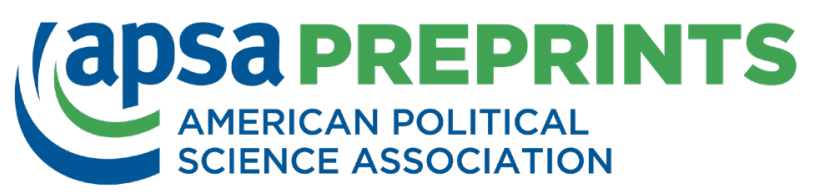

